\title{
RESEARCH INTO THE PROCESS OF LOADING WOOD ASSORTMENTS BY A TRACTOR-MOUNTED HYDRAULIC MANIPULATOR OF A TRACTOR-TRAILER TRAIN
}

\author{
Mikhail Smirnov*, Yurii Shirnin, Alexander Shirnin, Yurii Andrianov \\ Volga State University of Technology, Russia
}

In order to gain competitive advantages, managers of present-day supply chain systems need to achieve critical operation goals, such as keeping flexible fabrication schedule, retaining product quality, maintaining timely delivery, and lowering overall operating costs. Inspired by these factors, this study developed a decision model for managers to investigate the joint impacts of quality-assured issues, overtime, and multi-shipment plan on optimal fabrication-shipment policy and on diverse system parameters of the economic production quantity (EPQ)-based supply chain system. An imperfect fabrication process producing perfect quality, repairable, and scrap items is assumed in the proposed system, along with assumptions of a flexible overtime schedule to partially expedite fabrication rate and a discontinuous multi-delivery policy for distributing end products. With a help from mathematical modeling and optimization method, the closed-form optimal fabrication-shipment policy is derived. A numerical example was employed to demonstrate applicability of our result and to expose critical managerial information of the system for supporting decision-making.

Key words: tractor-trailer train, tractor-mounted hydraulic manipulator, assortments, loading, energy consumptionsoftware

\section{INTRODUCTION}

The transport component of timber harvesting industry technological process is the most capital-intensive. Therefore increasing the efficiency of functioning of a wood enterprise as a whole demands perfection of design and state of timber hauling roads, as well as the processes of loading, transportation and unloading of forest products [1-6]. Self-loading tractor-trailer trains widely used in hauling forest products in Russia have a truck-mounted hydraulic manipulator, load opportunities of which are frequently used inefficiently [7-12]. Further increase in productivity and decrease in of self-loading tractor-trailer trains operation demand carrying out additional research and scientific substantiation of reduction of duration of their stay in the points of forest products loading and unloading and better use of load op-portunities of the loading manipulator [8-10].

The purpose of this paper is to substantiate the possibility of reduction of duration and energy costs of forest products loading with a truck-mounted hydraulic manipulator of a self-loading tractor-trailer train.

The research objectives are to

1. carry out work measurement of the process of assortment loading with a truck-mounted hydraulic manipulator of a self-loading tractor-trailer train at a timber harvesting the enterprise;

2. analyse the conditions of rational use of the load moment of a truck-mounted hydraulic manipulator;

3. substantiate rational duration of tractor-trailer trains loading in a wood-cutting area;
4. develop a technique for energy costs calculation under forest products loading with a truck-mounted hydraulic manipulator of a self-loading tractor-trailer train.

\section{Research methods and results}

Work measurement of self-loading timber hauling tractor-trailer trains were conducted in July 2017 at 000 Pine timber harvesting enterprise of the Republic of Mari El. Assortments were hauled by tractor-trailer trains consisting of KAMAZ-43101 truck, a KAMAZ-GKB-9383 semitrailer and LV-185 hydraulic manipulator. The assortments harvested and hauled were I $=6.5 \mathrm{~m}$ long.

The results of work measurement are presented in Tab. 1. The process of assortments loading with a hydraulic manipulator was studied. The number of logs gripped with a hydraulic manipulator grapple in a single action (column 2) and average diameter of assortments (column 3) were measured. These data given, the volume of a bundle being loaded with a hydraulic manipulator in a single action was calculated (column 4).

Under the research done the hydraulic manipulator simultaneously gripped hardly more than two logs on the average, the average volume of a log was $0.28 \mathrm{~m}^{2}$, and the average volume of an assortment bundle loaded equaled $0.898 \mathrm{~m}^{3}$.

The arrangement of an assortments stack of logs against the tractor-trailer train was also documented. The relative positioning of a stack of logs and a tractor-trailer train defines the dis-tance of forest products moving during the loading operation, the duration of loading and size of 
the load moment necessary (Fig. 1).

A load moment of the hydraulic manipulator $(\mathrm{kN} \cdot \mathrm{m})$ necessary for assortment loading and unloading is calculated according to the following formula (8)

where $y$ is pine green density, $y=8430 \mathrm{~N} / \mathrm{m}^{3}$ [12]; $Q_{a}$ is volume of a bundle being loaded, $\mathrm{m}^{3}$.

The volume of a bundle being loaded [13]

Table 1: Parameters of assortment bundles loaded onto a tractor-trailer train

\begin{tabular}{|c|c|c|c|}
\hline Number & $\begin{array}{l}\text { Number of } \\
\text { logs in a } \\
\text { bundle } n \text {, } \\
\text { pcs }\end{array}$ & \begin{tabular}{|c|} 
Average \\
diameter of \\
assortments \\
$\mathrm{d}, \mathrm{m}$
\end{tabular} & $\begin{array}{c}\text { Volume of a } \\
\text { bundle being } \\
\text { loaded } \mathrm{Vb}, \mathrm{m}^{3}\end{array}$ \\
\hline 1 & 3 & 0.25 & 0.957 \\
\hline 2 & 3 & 0.24 & 0.882 \\
\hline 3 & 2 & 0.28 & 0.800 \\
\hline 4 & 1 & 0.49 & 1.225 \\
\hline 5 & 3 & 0.22 & 0.775 \\
\hline 6 & 1 & 0.48 & 1.176 \\
\hline 7 & 3 & 0.2 & 0.612 \\
\hline 8 & 2 & 0.32 & 1.045 \\
\hline 9 & 2 & 0.30 & 0.918 \\
\hline 10 & 1 & 0.42 & 0.900 \\
\hline 11 & 2 & 0.26 & 0.690 \\
\hline 12 & 1 & 0.45 & 1.033 \\
\hline 13 & 1 & 0.47 & 1.127 \\
\hline 14 & 3 & 0.22 & 0.741 \\
\hline 15 & 3 & 0.22 & 0.775 \\
\hline 16 & 1 & 0.43 & 0.943 \\
\hline 17 & 3 & 0.22 & 0.741 \\
\hline 18 & 4 & 0.19 & 0.737 \\
\hline 19 & 2 & 0.31 & 0.981 \\
\hline $\begin{array}{c}\text { Total } \\
\text { number }\end{array}$ & 41 & & 17.058 \\
\hline $\begin{array}{l}\text { Mean } \\
\text { value }\end{array}$ & 2.16 & 0.28 & 0.898 \\
\hline
\end{tabular}

where $\mathrm{d}$ is assortments diameter, $\mathrm{m}$; la is assortments length, $\mathrm{m}$; na is the number of logs in a bundle gripped with a hydraulic manipulator grapple in a single action, pcs.

The necessary boom reach rh of a hydraulic manipulator in case the bundle and the tractor-trailer train are arranged as in the scheme (Fig. 1) can be calculated according to the formula

where $B$ is overall breadth of the tractor-trailer train, $B=$ $2.5 \mathrm{~m}$; $\mathrm{c}$ is the distance between the stack of logs and the tractor-trailer train, $\mathrm{c}=0.5 \mathrm{~m}$; la $=6.5 \mathrm{~m}$.

Load moment of LV-185 hydraulic manipulator at full

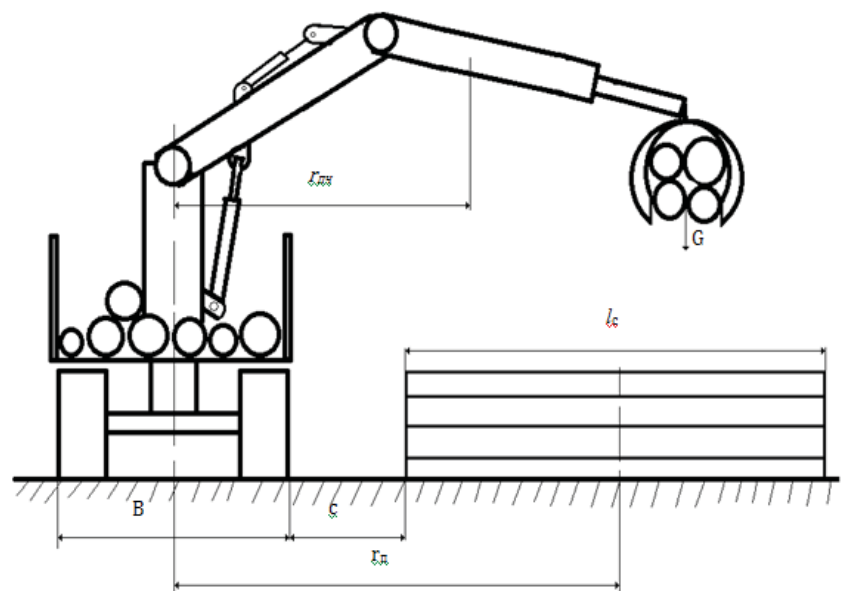

Figure 1: Assortments loading with a hydraulic manipulator of a tractor-trailer train

boom extension according to its technical specification [12] equals $90 \mathrm{kN} \cdot \mathrm{m}$.

$\mathrm{M}_{\mathrm{b}}=10^{3} \cdot \gamma \cdot Q_{a} \cdot a$

Calculation of a necessary load moment for LV-185 hydraulic manipulator, given $\mathrm{rh}=5 \mathrm{~m}$, are presented in Tab. 2.

$Q_{a}=\left(\frac{\pi \cdot d^{2}}{4} \cdot l_{a}\right) \cdot n_{a}$

The research conducted shows, that the load moment of the truck-mounted hydraulic ma-nipulator during assortments loading under the given conditions averages $37.84 \mathrm{kN} \cdot \mathrm{m}$ or 42 per cent of the maximal load moment which is $90 \mathrm{kN} \cdot \mathrm{m}$ for LV-185.

Thus, load opportunities of the manipulator are underused.

$r_{h}=\frac{B}{2}+c+\frac{l_{a}}{2}$

For rational use of load opportunities of the manipulator it is neces-sary to increase the volume of an assortment bundle being loaded in a single action. However the in-

$$
r_{h}=\frac{2.5}{2}+0.5+\frac{6.5}{2}=5(\mathrm{~m})
$$

crease in volume of an assortment bundle being loaded is limited to the capacity of gripping assortments with a hydraulic manipulator grapple.

Let us define the degree of using the section area of grapple tongs $\mathrm{Ft}$, its grab being losed. The section area of grapple tongs for KD-185 manipulator equals $\mathrm{Ft}=0.35$ $\mathrm{m} 3$. The real cross-section area of an assortment bundle being loaded with a manipulator can be found according to the formula (1)

where $\mathrm{Kb}$ is a bundle stacking factor, for assortments $\mathrm{Kb}=0.6 \ldots 0.7$ [14].

According to our studies

Thus, the section area of grapple tongs usage consti 
Table 2: Calculation results for a necessary load moment of a hydraulic manipulator

\begin{tabular}{|c|c|c|c|}
\hline \multirow{2}{*}{ Number } & \multirow{2}{*}{$\begin{array}{l}\text { Volume of a bundle of } \\
\text { assortments } \mathrm{Qa}, \mathrm{m}^{3}\end{array}$} & \multicolumn{2}{|c|}{ Load moment } \\
\hline & & $\mathrm{m}^{3} \cdot \mathrm{m}$ & $\mathrm{kN} \cdot \mathrm{m}$ \\
\hline 1 & 0.957 & 4.784 & 40.326 \\
\hline 2 & 0.882 & 4.409 & 37.164 \\
\hline 3 & 0.800 & 4.000 & 33.723 \\
\hline 4 & 1.225 & 6.126 & 51.638 \\
\hline 5 & 0.775 & 3.875 & 32.664 \\
\hline 6 & 1.176 & 5.878 & 49.552 \\
\hline 7 & 0.612 & 3.062 & 25.808 \\
\hline 8 & 1.045 & 5.225 & 44.046 \\
\hline 9 & 0.918 & 4.592 & 38.713 \\
\hline 10 & 0.900 & 4.500 & 37.938 \\
\hline 11 & 0.690 & 3.449 & 29.078 \\
\hline 12 & 1.033 & 5.166 & 43.552 \\
\hline 13 & 1.127 & 5.636 & 47.509 \\
\hline 14 & 0.741 & 3.704 & 31.228 \\
\hline 15 & 0.775 & 3.875 & 32.664 \\
\hline 16 & 0.943 & 4.717 & 39.767 \\
\hline 17 & 0.741 & 3.704 & 31.228 \\
\hline 18 & 0.737 & 3.684 & 31.056 \\
\hline 19 & 0.981 & 4.904 & 41.337 \\
\hline $\begin{array}{l}\text { Total } \\
\text { number }\end{array}$ & 17.058 & & \\
\hline $\begin{array}{l}\text { Mean } \\
\text { value }\end{array}$ & 0.898 & & 37.84 \\
\hline
\end{tabular}

tutes only 57 her cent. The possible volume of assortment bundle being loaded under the full use of the section area of manipulator grapple tongs can be calculated according to the formula

Given the average volume of assortments of $0.28 \mathrm{~m} 3$, let us define the number of gripped logs in a single action using formula (2)

So, it is reasonable to grip 4 rather than 2 assortment logs out of a stack of logs because load moment of the manipulator and cross-section area of grapple tongs af- ford to do this.

Let us consider how it will affect the duration and energy

$$
F_{t}=\frac{v_{b}}{l_{a} \cdot K_{b}}
$$

expenses of assortments load-ing in a wood-cutting area. For the time being there are no specifications for the duration of for-est products loading with a track-mounted

$$
F_{t}=\frac{0.898}{6.5 \cdot 0.7}=0.20\left(\mathrm{~m}^{2}\right)
$$

hydraulic manipulator depending on their dimensional characteristics and other parameters. Therefore, to establish the factors effecting the duration of assortments loading with a track-mounted hydraulic manipulator, we shall take advantage of the experimental research done

$$
\begin{aligned}
& Q_{a}=F_{t} \cdot l_{a} \cdot K_{b} \\
& Q_{a}=0.35 \cdot 6.5 \cdot 0.7=1.60\left(\mathrm{~m}^{3}\right)
\end{aligned}
$$

by us earlier [15-16] in production conditions through work mea-surement at various timber harvesting enterprises. As a result of work measurement data process-

$$
n_{a}=\frac{4 \cdot Q_{a}}{\pi \cdot d^{2} \cdot l_{a}}=\frac{4 \cdot 1.6}{3.14 \cdot 0.28^{2} \cdot 6.5}=4
$$

ing, regression equations are obtained for duration of assortments loading with a track-mounted hydraulic manipulator of a tractor-trailer train

where $t_{\text {dur }}$ is duration of loading of $1 \mathrm{~m}^{3}$ of timber prod-

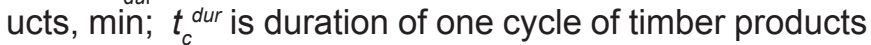
loading, min; $I_{m}$ is the length of the distance of timber products move-ment in a horizontal plane from the stack of logs to the tractor-trailer train, $\mathrm{m} ; h_{s}$ is a stack of logs height (defines the height of timber products lifting vertically), $\mathrm{m}$.

The calculations carried out using equation (7) show, when a manipulator grapple grips two assortments the duration of a loading cycle equals $0.63 \mathrm{~min}$, and when the number of assortments is four the duration of a loading cycle increases up to $0.76 \mathrm{~min}$, or by 21 per cent. The initial data for further calculations are accepted the same as for research in enterprise environ-ment: $I_{a}=6.5 \mathrm{~m} ; I_{m}=$ $5.0 \mathrm{~m} ; \mathrm{d}=28 \mathrm{~cm}$.

In this case the necessary number of loading cycles will

$$
\begin{aligned}
t_{\text {dur }}= & 2.1670-0.0470 \cdot l_{a}-0.0068 \cdot d+0.124 \cdot l_{m}-0.0052 \cdot l_{a} \cdot d- \\
& -0.0076 \cdot l_{a} \cdot l_{m}-0.0015 \cdot d \cdot l_{m}+0.0003 \cdot l_{a} \cdot d \cdot l_{m}, \\
t_{c}^{d u r}= & 0.3494+0.0706 \cdot n_{a}-0.1220 \cdot h_{s}+0.0468 \cdot l_{m}+0.0145 \cdot h_{s} \cdot l_{m},
\end{aligned}
$$


decrease. Given average trip load of $20 \mathrm{~m}^{3}$ in hauling assortments by KAMAZ-43101 + KAMAZ-GKB-9383 + LV-185 tractor-trailer train, manipulator grapple gripping of two assortments will require 25 cycles of loading, and under gripping of four assortments the necessary number of cycles will be reduced up to 13. Thus total duration of loading of the tractor-trailer train (net time of loading) will decrease by $6 \mathrm{~min}$, or 37 per cent.

When the manipulator works under full boom extension $\left(r_{f}=7.8 \mathrm{~m}\right)$ and grips four as-sortments, the duration of a loading cycle will make $0.85 \mathrm{~min}$ and will increase by 35 per cent. Therefore full boom extension is not recommended. The tractor-trailer train should approach the stack of logs as close as possible when loading.

Let us define the amount of energy costs for assortments loading on a tractor-trailer train. $E_{a l}$ energy costs in $\mathrm{kW} \cdot \mathrm{h} / \mathrm{m}^{3}$ on assortment loading by a self-loading tractor-trailer train equals the sum of energy cost per unit for movement of the manipulator during loading, $E_{m m}$, and on assortments stacking, $E_{\text {as }}$ [17-19].

where $G_{b a}=Q_{a} \cdot V$ is gravity force of assortments bundle being loaded (unloaded) by a manipulator in a single action, $k N ; G_{r m}$ is gravity force of a revolving part of a manipulator, $\mathrm{kN} ; \mathrm{G}_{b d}$ - gravity force of a boom with a dipperstick, $\mathrm{kN} ; h$ is mean height of assortments lifting when loading them into tractor-trailer train bunks from the stack, $\mathrm{m} ; \psi_{b d}$ is the factor taking into account the increase in a power consumption due to unproductive movements of a boom with a dipperstick; $\psi_{r m}$ is the factor taking into account the increase in a power consumption due to unproductive movements of a manipulator revolving part; $r_{r}$ is the distance from the vertical revolving axis of a manipulator central pole in a horizontal plane to the centre of the assortments, $\mathrm{m} ; r_{b}$ is horizontal distance from boom pivot point to its gravity centre, $\mathrm{m} ; r_{r p}$ is the distance be-tween the vertical axis of central pole revolving and gravity centre of a revolving part, $\mathrm{m} ; \mu_{1}$ is friction ratio of a manipulator central pole against the turning circle; $\lambda_{h}$ is the turning angle of a pole with a manipulator in a horizontal plane, rad; $\lambda_{v}$ is the turning angle of a boom with a dip-perstick vertically, rad; $\mathrm{m}^{2}=M_{\mathrm{a}} / \mathrm{Q}_{\mathrm{a}}$ is the number of loading (unloading) cycles of the volume of truckload of a tractor-trailer train; $Q_{a}$ is the volume of assortments loaded (unloaded) by a manipulator in a single action, $\mathrm{m}^{3} ; \eta_{p r}$ is efficiency factor of energy transfer from the engine to the pole revolving mechanism; $\eta_{m c}$ is efficiency factor of energy transfer from the engine to the manipulator control mechanism.

As it is evident in Fig.2, in comparison with energy costs at $n_{a}=3$ the decrease of energy costs at $n_{a}=4$ will be 24 per cent, whereas at $n_{a}=5$ the reduction of energy costs will amount 36 per cent. The calculation is executed for the volume of assortments $Q=1.6 \mathrm{~m}^{3}$ loaded in a single action.

Using eq. (5) let us plot a graph (Fig. 3).

It is evident that desirable volume of assortments $(Q=$ $1.6 \mathrm{~m}^{3}$ ) loaded by a manipulator in a single action may be achieved under the following combinations of assortments quantity and diameters: $n_{a}=3, d=0.323 \mathrm{~m}$; $n_{a}=4, d=0.28 \mathrm{~m} ; n_{a}=5, d=0.25 \mathrm{~m}$.

\section{REFERENCES}

1. Brown M., \& Chaffarigan M., (2016). Timber truck payload management with differ-ent in-forest weighing strategies in Australia. Croatian Journal of Forest Engineering, 37(1), 131-138.

2. Kabeš A., Dvorak J., \& Natov P., (2014). Operation times in John Deere $1110 \mathrm{E}$ for-warders in regeneration felling. Journal of Forest Science, 60(6), 248253.

3. Pandur Z., Šušnjar M., Korvat P., \& Zoricetal M., (2015). Ispitivanje tehničkih značajki novešumske poluprikolice «Lika». Nova mehanizacija šumarstva: Časopis za teoriju i praksu šumarskoga inženjerstva, 36, 19-32.

4. Mokhirev, P. A., Zyryanov, M., Ryabova, G. T., \& Vititnev, A. [2019]. Evaluation of possi-bility of obtaining woodchips from wood residues. Journal of Applied Engineering Science, 17(2), 140-143.

5. Johnson E., (2015). Zambon bros logging does it all-well: Vermont contractors are meticulous about equipment and job quality. Northern Logger and Timber Process, 8(63), 14-17.

6. Pozdnyakova, O. M., Mokhirev, P. A., \& Ryabova, G. T. [2018]. Comprehensive evaluation of technological measures for increasing availability of wood resources. Journal of Applied Engineering Science, 16(4), 565-569.

$$
\begin{gathered}
E_{a l}=E_{a s}+E_{m m}= \\
\frac{m_{2}}{3600 \cdot M_{a}} \cdot\left(\frac{2 \cdot G_{b d} \cdot r_{b} \cdot \lambda_{b} \cdot \psi_{b}}{\eta_{p r}}+\frac{2 \cdot G_{r m} \cdot r_{r p} \cdot \lambda_{p} \cdot \mu_{1} \cdot \psi_{r m}}{\eta_{m c}}-\right)+\frac{G_{\mathrm{ba}}}{3600 \cdot M_{a}} \cdot \\
\left(\frac{h_{l} \cdot \psi_{b d}}{\eta_{p r}}+\frac{r_{r} \cdot \lambda_{h} \cdot \mu_{1} \cdot \psi_{r m}}{\eta_{m c}}\right)=\frac{1}{3600 \cdot n_{a} \cdot V} \cdot \\
\left(-\frac{2 \cdot G_{b d} \cdot r_{b} \cdot \lambda_{b} \cdot \psi_{b}}{\eta_{p r}}+\frac{2 \cdot G_{r m} \cdot r_{r p} \cdot \lambda_{p} \cdot \mu_{1} \cdot \psi_{r m}}{\eta_{m c}}-\right)+\frac{\gamma \cdot V \cdot n_{a}}{3600 \cdot M_{a}} \cdot\left(\frac{h_{l} \cdot \psi_{b d}}{\eta_{p r}}+\frac{r_{r} \cdot \lambda_{h} \cdot \mu_{1} \cdot \psi_{r m}}{\eta_{m c}}\right)
\end{gathered}
$$


$E_{\text {na }}, \mathrm{kWh} / \mathrm{m}^{3}$

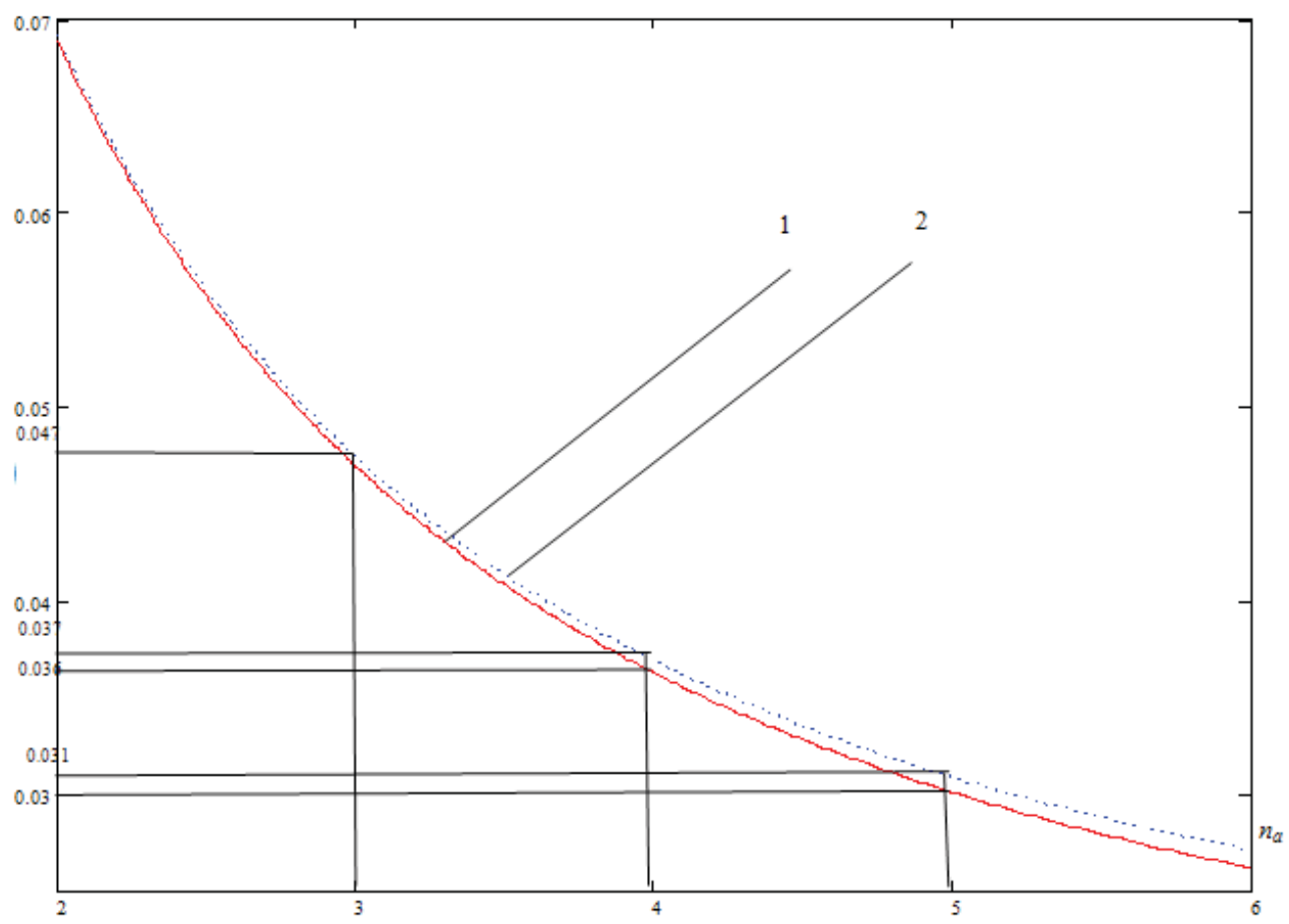

Figure 2: Dependence of energy costs during assortments bundle loading on num-ber of assortments $\left(n_{a}\right)$ loaded in a single action with boom reach $(r)$ of the manipulator of a self-loading tractor-trailer train: $1-r=5 m ; 2-r=7.8 \mathrm{~m}$

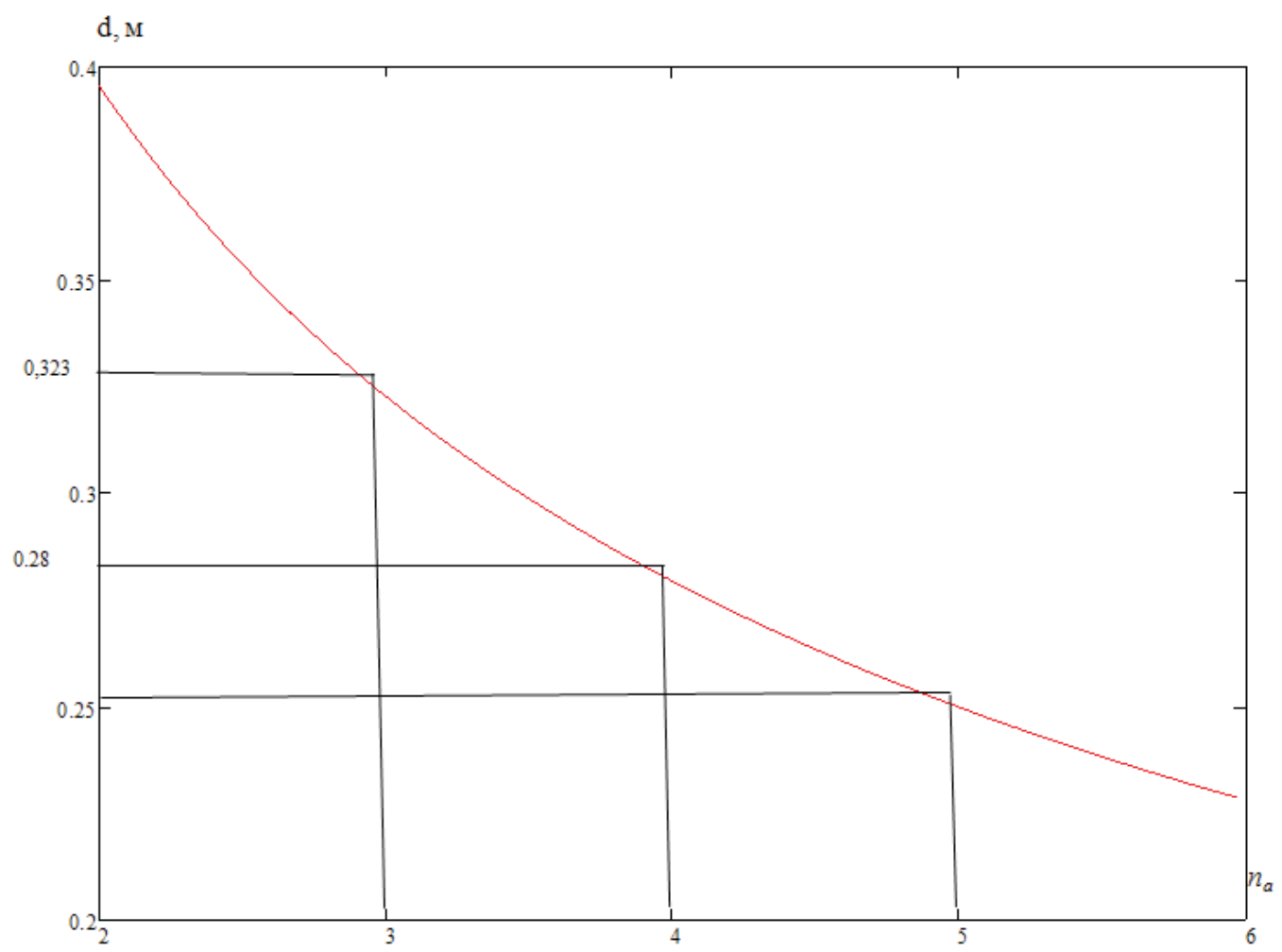

Figure 3: Correlation of $d$ assortments diameters and their na number in the volume of a bundle of assortments loaded in a single action $\left(Q_{a}=1.60 \mathrm{~m}^{3}\right)$ with $l_{a}=6.5 \mathrm{~m}$ 
7. Shirnin Yu. A., (1996). Technique and machines for felling-area works during assort-ment hauling: Study guide. Yoshkar-Ola: MarSTU.

8. Smirnov, M., \& Andrianov, Y. [2018]. Technologies of timber assortments hauling by tractor-trailer train squads. Journal of Applied Engineering Science, 16(2), 254-257.

9. Smirnov M. Yu. (2003). Increasing the efficiency of timber hauling by tractor-trailer trains. Yoshkar-Ola: MarSTU.

10. Smirnov M.Yu. \& Bakulina I.R., (2010). Basic principles of furnishing a loading-transportation squad звена of tractor-trailer trains. Yoshkar-Ola: MarSTU.

11. Gorokhovsky K. F. \& Livshits N.V., (1987). Basic principles of process design for timber cutting and storage facilities arrangement. Moscow: Forestry.

12. Shirnin Yu. A., Yakimovich S. B., Chemodanov A. N., \& Tsaryov Ye. M., (1999). Technology and equipment of timber harvesting enterprises. Reference materials: Study guide. Yoshkar-Ola: MarSTU.

13. Shirnin Yu. A., (2014). Theory of transporting operations during timber harvesting: Study guide. Yoshkar-Ola: VSUT.

14. Smirnov M. Yu. (1987). Study of stacked-volume ratio change of a bundle of trees in view of its length. Moscow: VNIPIE lesprom.

15. Andrianov Yu. S., Smirnov M. Yu., \& Popova N. A., (1998). Contemporary problems of forestry complex of the Volga-Vyatka region. (str. 57-59). Yoshkar-Ola: MarSTU.
16. Smirnov M. Yu., \& Andrianov Yu. S., (2000). Experimental assessment of duration of as-sortment loading with a tractor-trailer mounted hydraulic manipulator. U Technology of tim-ber in-dustry and transport. (str. 943-102). Ekaterinburg: USFA.

17. Shirnin Yu.A., \& Shirnin A.Yu., (2013). Modeling of power inputs of adaptive-modular systems of machines at combined timber hauling. Vestnik MGUL. Lesnoy vestnik, 3, 166-175.

18. Yurievich, S. A., \& Aleksandrovich, S. Y. [2016]. Comparison of systems of cars for extreme conditions logging. Journal of Applied Engineering Science, 14(2), 206-212.

19. Shirnin, Y., Denisov, S., \& Shirnin, A. [2016]. Feasibility demonstration of technologies for the development of pine burnt woods with the aim of reestablishment of the pine stand from the seeds remaining in tree crowns after a low fire. Journal of Applied Engineering Science, 14(3), 391-400. 